\title{
ERRATUM
}

Bernard Haussy • Jean François Ganghoffer

\section{Discrete probabilistic models of damage and adhesion}

Published online: 30 May 2006

(C) Springer-Verlag 2006

Archive of Applied Mechanics (2005) 75(6-7):338-354

Due to a processing error, the spelling of the title was incorrect. The correct title should read:

Discrete probabilistic models of damage and adhesion

The online version of the original article can be found at http://dx.doi.org/10.1007/s00419-005-0421-6

B. Haussy $(\varangle)$

Ecole Supérieure d'Electronique de l'Ouest. 4, rue Merlet de la Boulaye, BP 30926, 49009 Angers Cedex, France

E-mail: bernard.haussy@eseo.fr 